\title{
Extracorporeal Membrane Oxygenation in Drug Overdose: A Clinical Case Series
}

\author{
C. Vignesh, Madhan Kumar', Ramesh Venkataraman, Senthilkumar Rajagopal, Nagarajan Ramakrishnan, Babu K. Abraham \\ Departments of Critical Care Medicine and ${ }^{1}$ Cardiothoracic surgery, Mechanical Circulatory Support and Transplantation, Apollo Hospitals, Chennai, Tamil Nadu, India
}

\section{Abstract}

Overdose of cardiovascular medications such as beta blockers and calcium channel blockers cause impaired cardiac contractility, vasoplegia, and/or rhythm disturbances. In addition to conventional management of limiting absorption, increasing elimination and hemodynamic support intravenous (IV) calcium infusion, hyperinsulinemia-euglycemia therapy, glucagon infusion, and IV lipid emulsion have been tried. Extracorporeal circulatory assist device support has been reported as a rescue therapy in overdose refractory to maximal medical therapy. We report three patients with cardiovascular medication overdose presenting with profound cardiovascular instability refractory to medical therapy. Venoarterial extracorporeal membrane oxygenation support (VA ECMO) was initiated to provide hemodynamic support. Despite the occurrence of device-associated complications, the outcome was good and all patients survived. VA ECMO may be considered in patients with severe refractory shock due to cardiotoxic medication overdose.

Keywords: Beta blockers, calcium channel blockers, circulatory assist device, drug overdose, extracorporeal membrane oxygenation

\section{INTRODUCTION}

Cardiovascular medication overdose constitutes about $3.5 \%$ of all drug overdoses, and it carries a mortality of about $16 \%{ }^{[1]}$ Calcium channel blockers (CCBs) and beta blockers alone account for more than $65 \%$ of these deaths. ${ }^{[2]}$ The cardiovascular collapse associated with these drugs is due to impaired cardiac contractility, profound vasodilation, and/or rhythm disturbances. Treatment with volume resuscitation, vasopressors, hyperinsulinemia-euglycemia therapy, glucagon, and temporary pacing has been successful when the overdose is mild to moderate ${ }^{[3]}$ In severe overdose, with shock refractory to maximal medical therapy, circulatory assist device has been used successfully. ${ }^{[4]}$ This case series describes the use of venoarterial extracorporeal membrane oxygenation (VA ECMO) circulatory support as a salvage therapy in patients resistant to maximal medical management.

\section{Case Reports}

\section{Case 1}

A 29-year-old female was admitted to the emergency department with severe hypotension and vomiting, $8 \mathrm{~h}$ following ingestion of 40 tablets of amlodipine ( $10 \mathrm{mg}$ each; total $400 \mathrm{mg}$ ).

\begin{tabular}{|l|l|}
\hline \multicolumn{3}{c|}{ Access this article online } \\
\hline Quick Response Code: & Website: \\
& www.ijccm.org \\
\hline
\end{tabular}

She was conscious, oriented with blood pressure (BP) of $70 / 40 \mathrm{mmHg}$; heart rate (HR) of $55 / \mathrm{min}$; respiratory rate (RR) of $30 / \mathrm{min}$; oxygen saturation $\left(\mathrm{SpO}_{2}\right)$ of $92 \%$ and warm peripheries. Gut decontamination with activated charcoal and resuscitation with boluses of intravenous (IV) crystalloids, calcium gluconate, and norepinephrine infusion was done.

On arrival to Intensive Care Unit (ICU), her BP was $80 / 40 \mathrm{mmHg}$. Arterial blood gas (ABG) analysis revealed metabolic acidosis with $\mathrm{pH}$ of 7.25 and serum lactate of $5.2 \mathrm{mmol} / \mathrm{dL}$. Her echocardiography showed normal left ventricular (LV) function. She was electively intubated and ventilated and resuscitated with a total volume of $5.94 \mathrm{~L}$ of IV crystalloids. She was also initiated on standard doses of IV $10 \%$ calcium gluconate; IV 20\% intralipid IV insulin, and IV glucagon [Table 1]. Despite $9 \mathrm{~h}$ of aggressive resuscitation, her metabolic acidosis and hemodynamics worsened requiring

\begin{tabular}{|c|c|}
\hline $\begin{array}{r}\text { Department of Critical Care } \mathrm{M} \\
\text { Of }\end{array}$ & $\begin{array}{l}\text { Address for correspondence: Dr. C. Vignesh, } \\
\text { Vedicine, Apollo Hospitals, 21, Greams Lane, } \\
\text { Off Greams Road, Chennai, Tamil Nadu, India. } \\
\text { E-mail: vignesh.c.able@gmail.com }\end{array}$ \\
\hline \multicolumn{2}{|c|}{$\begin{array}{l}\text { This is an open access article distributed under the terms of the Creative Commons } \\
\text { Attribution-NonCommercial-ShareAlike } 3.0 \text { License, which allows others to remix, tweak, } \\
\text { and build upon the work non-commercially, as long as the author is credited and the } \\
\text { new creations are licensed under the identical terms. }\end{array}$} \\
\hline \multicolumn{2}{|c|}{ For reprints contact: reprints@medknow.com } \\
\hline $\begin{array}{l}\text { How to cite this article: } \mathrm{Vi} \\
\text { Rajagopal } \mathrm{S} \text {, Ramakrishnan } \mathrm{N} \text {, } \\
\text { oxygenation in drug overdose: } \\
\text { Med 2018;22:111-5. }\end{array}$ & $\begin{array}{l}\text { Vignesh C, Kumar M, Venkataraman R, } \\
\text { J, Abraham BK. Extracorporeal membrane } \\
\text { A clinical case series. Indian J Crit Care }\end{array}$ \\
\hline
\end{tabular}




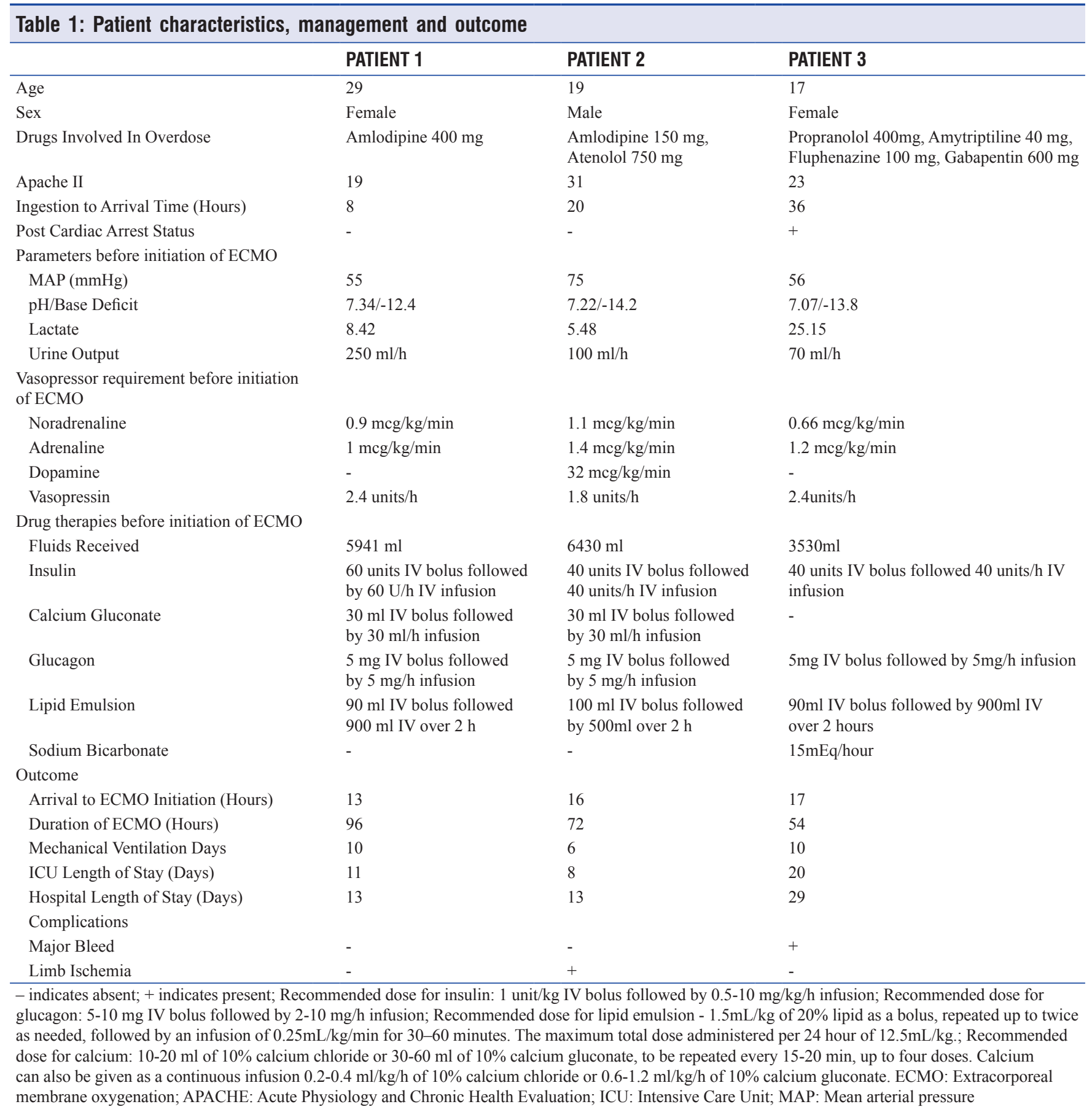

high doses of triple vasopressors (noradrenaline, adrenaline, and vasopressin). At this point of time, a decision to initiate peripheral VA ECMO was made. A 17-French cannula was inserted into the left femoral artery and a 19-French cannula into the right femoral vein. An additional 7-French cannula was placed in the left femoral artery to facilitate distal perfusion. VA ECMO was initiated at a flow of $3.7 \mathrm{~L} / \mathrm{min}$, and within $2 \mathrm{~h}$, her vasopressor requirement decreased significantly [Table 2]. Over the next $6 \mathrm{~h}$, her acidosis settled and lactate levels decreased. By the $2^{\text {nd }}$ day, despite significant improvement in her hemodynamics, her oxygenation worsened with clinical and radiological features suggestive of acute respiratory distress syndrome. By the $4^{\text {th }}$ day, she was changed over to a veno-venous ECMO, and by the $5^{\text {th }}$ day, it was decannulated.

She was successfully weaned off the ventilator and extubated by the $8^{\text {th }}$ day and discharged from the hospital on the $11^{\text {th }}$ day.

\section{Case 2}

A 19-year-old male was admitted to the ICU about $24 \mathrm{~h}$ after having ingested 30 tablets each of amlodipine $5 \mathrm{mg}$ and atenolol $25 \mathrm{mg}$. He was resuscitated in another hospital before the transfer. 
Vignesh, et al.: ECMO in drug overdose

\begin{tabular}{|c|c|c|c|c|c|c|c|c|c|}
\hline & \multicolumn{3}{|c|}{ Patient 1} & \multicolumn{3}{|c|}{ Patient 2} & \multicolumn{3}{|c|}{ Patient 3} \\
\hline & $\begin{array}{l}\text { Before } \\
\text { ECMO }\end{array}$ & $\begin{array}{c}4 \mathrm{~h} \text { after } \\
\text { ECMO }\end{array}$ & $\begin{array}{c}8 \mathrm{~h} \text { after } \\
\text { ECMO }\end{array}$ & $\begin{array}{l}\text { Before } \\
\text { ECMO }\end{array}$ & $\begin{array}{c}4 \text { h after } \\
\text { ECMO }\end{array}$ & $\begin{array}{c}8 \mathrm{~h} \text { after } \\
\text { ECMO }\end{array}$ & $\begin{array}{l}\text { Before } \\
\text { ECMO }\end{array}$ & $\begin{array}{c}4 \mathrm{~h} \text { after } \\
\text { ECMO }\end{array}$ & $\begin{array}{c}8 \mathrm{~h} \text { after } \\
\text { ECMO }\end{array}$ \\
\hline MAP & 55 & 85 & 88 & 75 & 78 & 90 & 56 & 56 & 61 \\
\hline $\mathrm{pH}$ & $7.34 /-12.4$ & $7.34 /-0.7$ & $7.47 /-4.3$ & $7.22 /-4.2$ & $7.56 / 1.4$ & $7.43 / 0.2$ & $7.07 /-13.8$ & $7.27 /-2.3$ & $7.45 / 0.7$ \\
\hline Lactate & 8.42 & 4.46 & 2.18 & 5.48 & 2.34 & 2.11 & 25.15 & 15.77 & 9.58 \\
\hline \multicolumn{10}{|l|}{ Vasopressor requirement } \\
\hline Noradrenaline (mcg/kg/min) & 0.9 & Nil & Nil & 1.1 & 0.16 & 0.16 & 0.66 & 0.13 & 0.1 \\
\hline Adrenaline $(\mathrm{mcg} / \mathrm{kg} / \mathrm{min})$ & 1 & 0.04 & 0.04 & 1.4 & Nil & Nil & 1.2 & 0.2 & 0.18 \\
\hline Vasopressin (units/h) & 2.4 & Nil & Nil & 1.8 & Nil & Nil & 2.4 & 1.8 & 1.8 \\
\hline Dopamine (mcg/kg/min) & & Nil & Nil & 32 & Nil & Nil & Nil & Nil & Nil \\
\hline
\end{tabular}

ECMO: Extracorporeal membrane oxygenation; MAP: Mean arterial pressure

On arrival to the ICU, he was on high dose of multiple vasopressors (noradrenaline, adrenaline, dopamine, and vasopressin) and had a temporary transvenous pacer in situ. His HR was $78 / \mathrm{min}$, in sinus rhythm and well above the pacing rate; $\mathrm{BP}$ was $90 / 50 \mathrm{mmHg}$; $\mathrm{SpO}_{2} 98 \%$ on $40 \% \mathrm{FiO}_{2}$; and central venous pressure was $24 \mathrm{mmHg}$ with cold peripheries. Echocardiogram showed normal LV function. Baseline ABG showed metabolic acidosis with a $\mathrm{pH}$ of 7.16 and lactate level of $4.59 \mathrm{mmol} / \mathrm{dL}$. He was resuscitated with standard doses of IV calcium gluconate, intralipid insulin, glucagon, and sodium bicarbonate [Table 1]. Despite $14 \mathrm{~h}$ of aggressive resuscitation, his vasopressor requirements increased and his shock worsened leading to initiation of a peripheral VA ECMO. The cannulation technique was similar to that used for case 1 and the ECMO flow was set at $4 \mathrm{~L} / \mathrm{min}$. Over the next $24 \mathrm{~h}$, his vasopressor requirements reduced significantly [Table 2] and he was completely weaned off vasopressor support. Urine output and lactate levels improved immediately. By the $4^{\text {th }}$ day, the calcium, insulin, and glucagon infusions were sequentially stopped. ECMO was decannulated on the $5^{\text {th }}$ day, and he was extubated on the $6^{\text {th }}$ day. However, on the $7^{\text {th }}$ day, he developed swelling and tenderness in the left lower limb over the arterial cannulation site, requiring fasciotomy for impending compartment syndrome. He responded well to treatment and was moved out of ICU on the $13^{\text {th }}$ day.

\section{Case 3}

A 17-year-old female was admitted following ingestion of multiple drugs (propranolol $40 \mathrm{mg}$ - 10 tablets; fluphenazine $10 \mathrm{mg}-10$ tablets; amitriptyline $10 \mathrm{mg}-4$ tablets; gabapentin $300 \mathrm{mg}-2$ tablets). Her initial resuscitation was done at an outside hospital.

She arrived to our hospital $36 \mathrm{~h}$ following ingestion of the drugs, intubated, and in severe shock. Evaluation revealed a left-sided pneumothorax for which intercostal drain was placed. She was volume resuscitated and initiated on the standard doses of IV calcium gluconate, insulin infusion, glucagon and intralipids [Table 1]. Her hemodynamics improved within $12 \mathrm{~h}$, with medical therapy. However, she went into supraventricular tachycardia followed by pulseless ventricular tachycardia that required $30 \mathrm{~min}$ of resuscitation for return of spontaneous circulation (ROSC). This episode was followed by refractory shock necessitating initiation of peripheral VA ECMO, which had to be converted into a central VA ECMO, with additional 14-French LV vent cannula as flows $>2.5 \mathrm{~L} / \mathrm{min}$ could not be achieved. Her vasopressor requirements decreased almost immediately [Table 2]. By the $4^{\text {th }}$ day, her hemodynamics improved to a level that the ECMO was weaned off and decannulated with minimal vasopressor support. Her stay in the ICU was a stormy and complicated by increased drainage from her chest drain requiring re-exploration, development of multiorgan failure - acute renal shutdown requiring renal replacement therapy, ischemic hepatitis, coagulopathy requiring multiple blood product transfusions, and ventilator-associated pneumonia requiring broad-spectrum antibiotics. She required renal replacement therapy till day 10 and was extubated on day 10 . On the $20^{\text {th }}$ day, she was shifted out of ICU and discharged from hospital on the $29^{\text {th }}$ day.

\section{Discussion}

The toxic effects of cardiac medication overdose are primarily an extension of their pharmacological activity. Beta blockers and CCB inhibit calcium influx into the cells, though by different mechanisms. ${ }^{[5,6]}$ The hemodynamic effects seen in their overdose are due to impaired cardiac contractility, vasoplegia, and/or rhythm disturbances.

The cornerstone of medical management for these drug overdoses consists of limiting their absorption and hemodynamic support until they are metabolized and eliminated from the body. Gastric decontamination with activated charcoal to limit the absorption can be attempted when done early. ${ }^{[7]}$ Volume resuscitation with fluids to overcome the relative hypovolemia associated with vasodilation and inotropic/vasopressor use are the mainstay. In CCB overdose, calcium infusion can be initiated in an attempt to overcome the calcium channel antagonism. The increased transcellular calcium gradient drives calcium intracellularly and antagonizes the effect of CCBs. ${ }^{[8]}$

In patients not responding to fluid resuscitation and inotropic support IV glucagon can be tried. Glucagon exerts its 
inotropic effects by activating adenylyl cyclase directly. The recommended dose is $5-10 \mathrm{mg}$ IV bolus followed by infusion at the rate of $2-10 \mathrm{mg} / \mathrm{h}$. The potential adverse effects include dose-dependent nausea, vomiting, hyperglycemia, and allergic reactions. ${ }^{[6]}$ High-dose insulin also has been used, and this improves the hemodynamics by exerting a direct inotropic effect and also by improving the carbohydrate metabolism in the myocardium. ${ }^{[9]}$ The recommended dose is $1 \mathrm{U} / \mathrm{kg} / \mathrm{h}$ following a bolus of $1 \mathrm{U} / \mathrm{kg}$. The infusion rate may be increased by $2 \mathrm{U} / \mathrm{kg} / \mathrm{h}$ every $10 \mathrm{~min}$ to a maximum dose of $10 \mathrm{U} / \mathrm{kg} / \mathrm{min}^{.[10]}$ Close monitoring of serum glucose, potassium, magnesium, and phosphorus is very important. Another drug used is IV lipid emulsions, and this creates an expanded lipid phase in the blood and traps the tissue-bound drugs to negate the toxic effects. ${ }^{[1]]}$ It is administered as $20 \%$ intralipid at a dose of $1.5 \mathrm{ml} / \mathrm{kg}$ bolus followed by infusion of $0.25-0.5 \mathrm{ml} / \mathrm{kg} / \mathrm{min} \cdot{ }^{[12]}$

In this case series of three patients, various combinations of cardioactive drug overdoses have been described. Patient 1 had taken CCB, patient 2 presented with a combination of beta blocker and $\mathrm{CCB}$, while patient 3 had taken a combination of beta blocker and other membrane stabilizing agents. Compared to other reported case series, this series had patients who were younger ${ }^{[13]}$ and none of them had any major comorbidities which could potentiate the cardiotoxic effects of the drugs. The APACHE score of the patients were 19,31, and 23, respectively.

Two of the patients were absolutely refractory to medical therapy and was in refractory shock with high lactate levels. Even though the third patient had transient hemodynamic response, she had an arrhythmic cardiac arrest $12 \mathrm{~h}$ into the medical therapy. The average time of arrival to the hospital was $18 \mathrm{~h}$. All of them received primary aid in another hospital and was referred for further care.

The principle of extracorporeal support in cardiovascular medication overdose is to support the hemodynamics and vital organ perfusion, until the medications have been eliminated from the system. ${ }^{[13-15]}$

The ECMO system used in this case series was Maquet Permanent Life Support System which include Rotaflow centrifugal pump, preconnected heparin and albumin-coated polyvinyl tubing, and quadrox-i membrane oxygenator with an integrated heat exchange system. All patients were heparinized just before insertion of vascular cannula and heparin infusion was continued to maintain activated clotting time of 160-180 s. ECMO flow was initiated at 3.5-4 L along with vasopressors support to maintain adequate mean arterial pressure. All patients were mechanically ventilated and other organ supports were provided as indicated. Once the hemodynamics improved, ECMO flow was gradually reduced and hemodynamic stability was assessed. If patient remained hemodynamically stable, ECMO was weaned off.

The average admission to ECMO initiation time in this series was $15.3 \mathrm{~h}$. Daubin et al., in a larger series of seventeen patient, reported admission to ECMO initiation time of $6.4 \pm 7.0 \mathrm{~h}^{\left[{ }^{[16]}\right.}$ One of the patients, in this series, had ECMO initiated only after restoration of ROSC from cardiac arrest, and this patient went on to develop multiorgan failure requiring organ supports including renal replacement therapy. In all the three patients, percutaneous peripheral arterial cannulations were performed in the bedside at the ICU. However, in one patient, adequate flow could not be achieved with the peripheral cannulation, and hence, central cannulation was done in the operating room. The average duration of ECMO support in this series was $74 \mathrm{~h}$. In the series reported by Daubin et al., the duration of ECMO flow was $4.5 \pm 2.4$ days. ${ }^{[15]}$ There was a rapid decrease in the inotropic requirements after initiation of ECMO, however, a small dose was continued to maintain a target mean arterial pressure. These findings are very similar to other reports.

In another case report, Weinberg et al. described successful use of ECMO in two patients with refractory vasodilatory shock associated with amlodipine poisoning. ${ }^{[16]}$

Like any other invasive devices, ECMO too comes with its set of complications. Limb ischemia is a well-documented complication of ECMO support. Daubin et al. reported ischemic complications in 10 of the 17 patients in their case series. ${ }^{[15]}$ However, Mégarbane et al. have reported lesser ischemic complications. ${ }^{[17]}$ One of the three patients in this case series developed limb ischemia in the cannulation side requiring fasciotomy, despite ensuring distal limb perfusion with additional distal cannulation. The other major reported complication of ECMO support is bleeding. In this case series, the patient who had central cannulation had major mediastinal bleeding requiring re-exploration and need for multiple blood products. Despite these complications all three patients survived and were discharged successfully.

\section{Conclusion}

Based on the limited evidence, there may be a role for the use of VA ECMO in patients with severe cardioactive drug overdose refractory to the medical therapy. Early initiation of ECMO support before organ failure or cardiac arrest sets in should be contemplated and may ensure the better overall outcome.

\section{Financial support and sponsorship}

Nil.

\section{Conflicts of interest}

There are no conflicts of interest.

\section{RefERenCes}

1. Lai MW, Klein-Schwartz W, Rodgers GC, Abrams JY, Haber DA, Bronstein AC, et al. 2005 Annual Report of the American Association of Poison Control Centers' national poisoning and exposure database. Clin Toxicol (Phila) 2006;44:803-932.

2. Massetti M, Bruno P, Babatasi G, Neri E, Khayat A. Cardiopulmonary bypass and severe drug intoxication. J Thorac Cardiovasc Surg 2000;120:424-5.

3. Olson KR, Erdman AR, Woolf AD, Scharman EJ, Christianson G, Caravati EM, et al. Calcium channel blocker ingestion: An 
evidence-based consensus guideline for out-of-hospital management. Clin Toxicol (Phila) 2005;43:797-822.

4. Albertson TE, Dawson A, de Latorre F, Hoffman RS, Hollander JE, Jaeger A, et al. TOX-ACLS: Toxicologic-oriented advanced cardiac life support. Ann Emerg Med 2001;37:S78-90.

5. Shepherd G. Treatment of poisoning caused by beta-adrenergic and calcium-channel blockers. Am J Health Syst Pharm 2006;63:1828-35.

6. Newton CR, Delgado JH, Gomez HF. Calcium and beta receptor antagonist overdose: A review and update of pharmacological principles and management. Semin Respir Crit Care Med 2002;23:19-25.

7. Kenny J. Treating overdose with calcium channel blockers. BMJ 1994;308:992-3.

8. Rizvi I, Ahmad A, Gupta A, Zaman S. Life-threatening calcium channel blocker overdose and its management. BMJ Case Rep 2012;2012. pii: bcr0120125643.

9. Lheureux PE, Zahir S, Gris M, Derrey AS, Penaloza A. Bench-to-bedside review: Hyperinsulinaemia/euglycaemia therapy in the management of overdose of calcium-channel blockers. Crit Care 2006;10:212.

10. Engebretsen KM, Kaczmarek KM, Morgan J, Holger JS. High-dose insulin therapy in beta-blocker and calcium channel-blocker poisoning. Clin Toxicol (Phila) 2011;49:277-83.

11. Palatnick W, Jelic T. Emergency department management of calcium-channel blocker, beta blocker, and digoxin toxicity. Emerg Med Pract 2014;16:1-9.

12. Gunja N, Graudins A. Management of cardiac arrest following poisoning. Emerg Med Australas 2011;23:16-22.

13. Baud FJ, Megarbane B, Deye N, Leprince P. Clinical review: Aggressive management and extracorporeal support for drug-induced cardiotoxicity. Crit Care 2007;11:207.

14. Johnson NJ, Gaieski DF, Allen SR, Perrone J, DeRoos F. A review of emergency cardiopulmonary bypass for severe poisoning by cardiotoxic drugs. J Med Toxicol 2013;9:54-60.

15. Daubin C, Lehoux P, Ivascau C, Tasle M, Bousta M, Lepage O, et al. Extracorporeal life support in severe drug intoxication: A retrospective cohort study of seventeen cases. Crit Care 2009;13:R138.

16. Weinberg RL, Bouchard NC, Abrams DC, Bacchetta M, Dzierba AL, Burkart KM, et al. Venoarterial extracorporeal membrane oxygenation for the management of massive amlodipine overdose. Perfusion 2014;29:53-6.

17. Mégarbane B, Leprince P, Deye N, Résière D, Guerrier G, Rettab S, et al. Emergency feasibility in medical Intensive Care Unit of extracorporeal life support for refractory cardiac arrest. Intensive Care Med 2007;33:758-64. 